\title{
RPSMDSM: Residential Power Scheduling and Modelling for Demand Side Management
}

\author{
Sheeraz Ahmed ${ }^{1,6 *}$, Ali Raza ${ }^{2,6}$, Shahryar Shafique1, Mukhtar Ahmad ${ }^{3}$ \\ M.Yousaf Ali Khan ${ }^{4}$, Asif Nawaz ${ }^{5,6}$, Rohi Tariq ${ }^{6}$ \\ ${ }^{1}$ IQRA National University, Peshawar, Pakistan \\ ${ }^{2}$ Edwardes College, Peshawar, Pakistan \\ ${ }^{3}$ Islamia College University, Peshawar, Pakistan \\ ${ }^{4}$ Gomal University, Dera Ismail Khan, Pakistan \\ ${ }^{5}$ Higher College of Technology, Dubai, UAE \\ ${ }^{6}$ Career Dynamics Research Centre, Peshawar, Pakistan \\ ${ }^{1}$ sheeraz.ahmad@inu.edu.pk, ${ }^{2}$ aliraza.edu@gmail.com, ${ }^{3}$ shahryar.shafique@inu.edu.pk, ${ }^{4}$ mukhtaricp@gmail.com, \\ ${ }^{5}$ myousafak@gu.edu.pk, ${ }^{6}$ anawaz@hct.ac.ae, 7rohitariq2014@gmail.com \\ *Corresponding author: Sheeraz Ahmed
}

\begin{abstract}
In third world countries like Pakistan, the production of electricity has been quickly reduced in past years due to rely on the fossil fuel. According to a survey conducted in 2017, the overall electrical energy capacity was 22,797MW, since the electrical grids have gone too old, therefore the efficiency of grids, goes down to nearly 17000MW. Significant addition of fossil fuel, hydro and nuclear is $64.2 \%, 29 \%$ and $5.8 \%$ respectively in the total electricity production in Pakistan. In 2018, the demand crossed 20,223MW, compared to peak generation of 15,400 to $15,700 \mathrm{MW}$ as by the Ministry of Water and Power. Country faces a deficit of almost 4000MW to 5000MW for the duration of 2019 hot summer term. Focus on one aspect considering Demand Side Management (DSM) cannot oversea the reduction of gap between power demand and customer supply, which eventually leads to the issue of load shedding. Hence, a scheduling scheme is proposed in this paper called RPSMDSM that is based on selection of those appliances that need to be only Turned-On, on priority during peak hours consuming minimum energy. The Home Energy Management (HEM) system is integrated between consumer and utility and bidirectional flow is presented in the scheme. During peak hours of electricity, the RPSMDSM is capable to persuade less power consumption and accomplish productivity in load management. Simulations show that RPSMDSM scheme helps in scheduling the electricity loads from peak price to off-peak
\end{abstract}


price hours. As a result, minimization in electricity cost as well as (Peak-to-Average Ratio) PAR are accomplished with sensible waiting time.

Keywords: Power Scheduling, Demand Side Management, Home Energy Management, Real-time Pricing, energy harvesting

\section{Introduction}

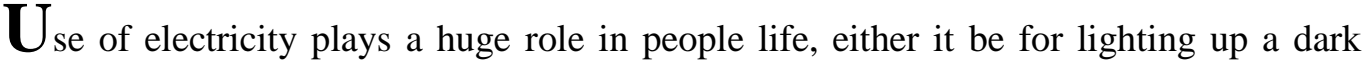
room or running our electric appliances but we may not notice it till we encounter power failure. People are so used to electricity that they don't even realize the presence of electricity, which is satisfying our everyday needs and the only time they think that it is missing, when due to some reason a power failure occurs [1].

\subsection{Conventional Power Systems}

Generally, conventional electrical energy systems transmit power through power plants to majority of consumers [2]. Usually, from power generation to homes, energy systems are uni-directional. Usually, power plants which are generators generate electrical energy, transmitted all the way through high voltage lines which are transporters to distribution centers, and the distributors, where it is stepped down to lower voltages and finally delivered to consumers $[3,4]$. Providing electricity to every customer forms a structure of a network which when connected to other nodes makes a power grid system.

Although rich with resources, the electric power generated in Pakistan is mainly dependent on non-renewable sources i-e natural gas, furnace oil, coal, nuclear as highlighted in Fig. 1, whereas other sources of energies being distinguished and categorized as nonrenewable sources [5]. The renewable energy usage, which helps to resolve the environmental concerns, such as to avoid transmission losses, originated from power plants are increasing on a daily basis [6].

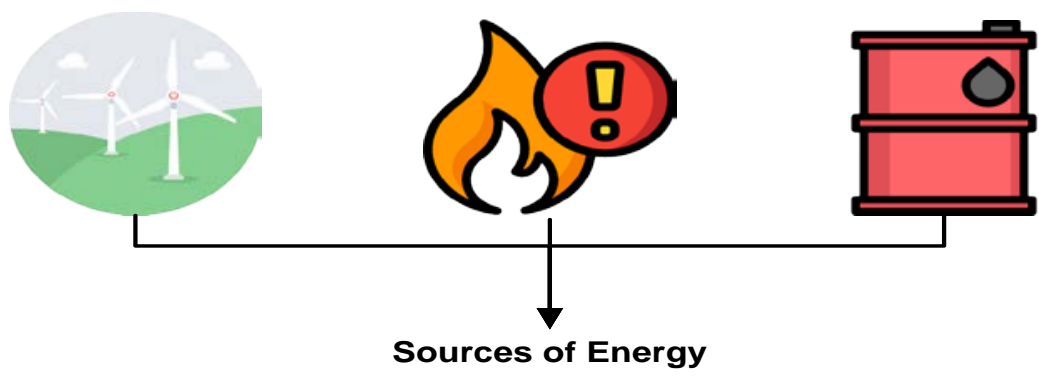

Fig. 1. Sources of Energies 


\section{$1.2 \quad$ Types of Energy}

Electricity generation is the process of generating electricity from other forms of energy, such as natural gas, coal, nuclear power, the sun and wind [1].There are two types of energy are used, which are shown the Fig. 2:

- Renewable Energy

- Non-Renewable Energy

\subsubsection{Renewable Energy}

In Pakistan, key producers renewable energy sources include solar system, geothermal energy source, wind mills, tidal source (hydroelectricity), and through biomass. Government is continuously making efforts to utilize natural resources for making energy [7].
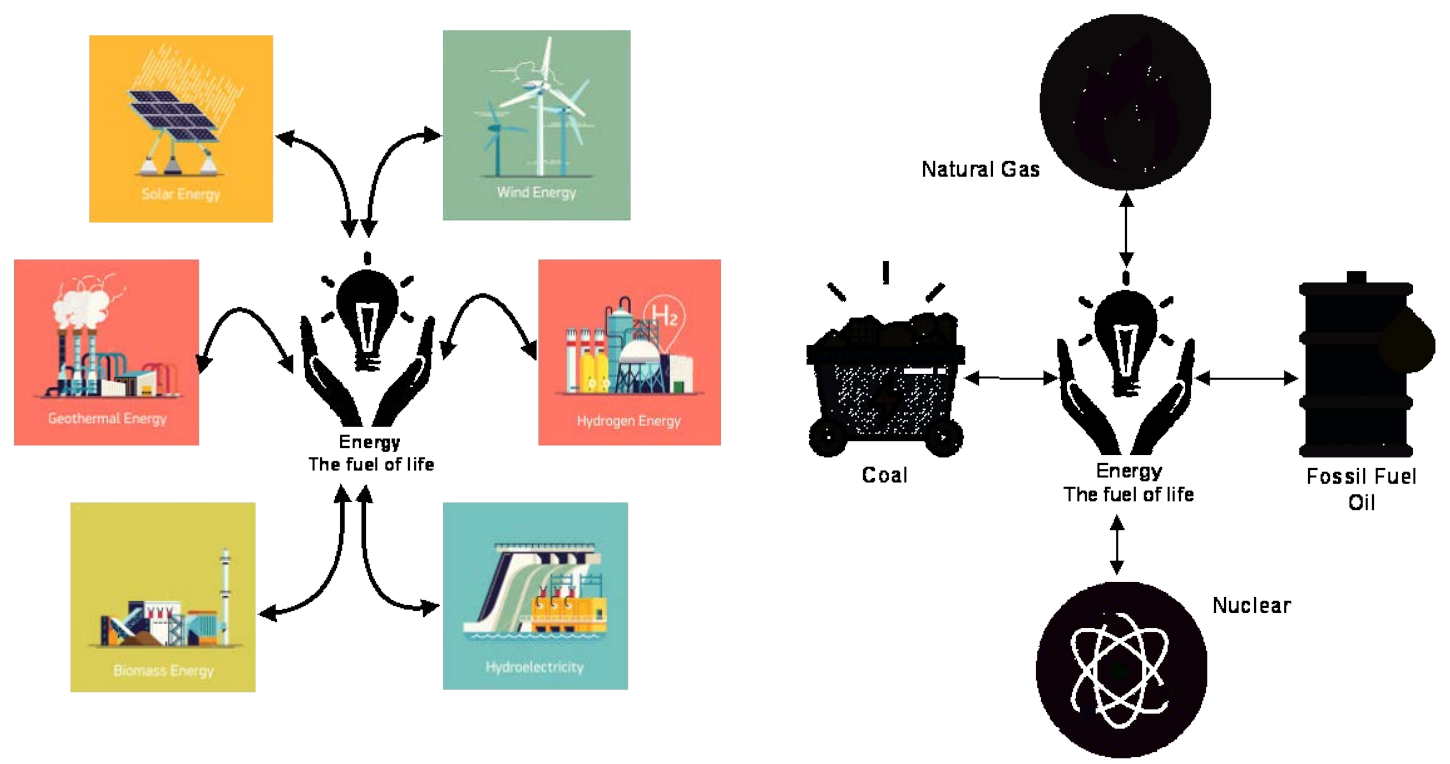

Fig. 2. Renewable vs Non-Renewable Energy Sources

\subsubsection{Non-Renewable Energy}

Most of the energy that is generated in Pakistan is by non-renewable energy source such as fossil fuels which includes, Natural Gas, Nuclear Energy, High Speed Diesel (HSD), and by means of Coal, and renewable source such as solar, hydel. Renewable Energy Resources (RERs) such as solar and wind are non-dispatch able, since they are random in nature $[6,8]$. Mostly the energy requirement around the world is being met by utilizing fossil fuels. But in contrast, immense utilization of such fuels causes serious environmental hazards in terms of harmful gases, used by highly industrialized world [9, 10] . 


\subsection{Generation Types of Electricity in Pakistan}

For the development and growth of the country in terms of economy, electricity is considered as a vital factor. In Pakistan, following main sources are used to produce electricity.

i. Hydro power

ii. Thermal (Gas/Steam/Furnace Oil)

iii. Nuclear power

iv. Renewable energy

In Pakistan, the production of electricity has been quickly reduced in past years due to rely on the fossil fuel. According to the survey [11] conducted in 2017, the overall electrical energy capacity was 22,797MW in 2017, since the electrical grids befall to aged, therefore the efficiency of grids, goes down to nearly $17000 \mathrm{MW}$. Significant addition of fossil fuel, hydro and nuclear is $64.2 \%, 29 \%$ and $5.8 \%$ respectively in the total electricity production in Pakistan. In 2018, the demand crossed 20,223MW, compared to peak generation of 15,400 to $15,700 \mathrm{MW}$ as by the Ministry of Water and Power. Country faces a deficit of almost 4000MW to 5000MW for the duration of 2019 hot summer term.

The prime foundation of energy supplies is inadequate to fulfill the current electrical power demands of Pakistan. Therefore country is facing severe power shortfall. To meet its energy requirements, every year government is spending billions of money to trade in oil, by yearly progress of approximately $1 \%$ of electricity is produced by two sources, which are renewable energy as well as non-renewable energy sources as shown in Fig. 3 [4].

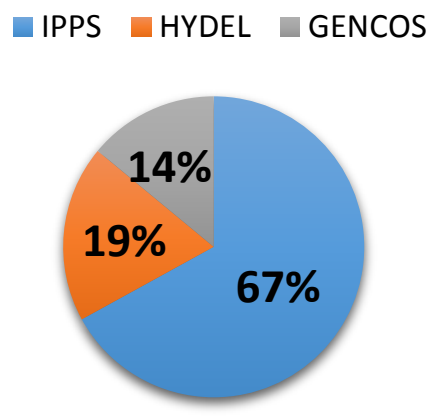

Fig. 3. Net Generation from Different Resources in Pakistan

Pakistan has started to take extensive initiatives. A well performance future power grid will be capable of in contributing (a) environmental friendly de-carbonization of energy sources, (b) improvement in efficiency to process conversion and end user (c) clean transportation [12]. 


\subsection{Downside of Conventional Grid that leads to Smart Grid}

Currently, demand for electrical energy is escalating into more than a few nations. Thus, the issue of managing electrical power straight forwardly affected industrialized growth, as well as economic, and environmental society. At the same time, the overall infrastructure of electrical system is too matured. To face upcoming future challenges, the idea of making a grid smarter has been turned into a frequent option for the 21st century $[13,14,15]$.

Since in Pakistan, the electrical lattice is too old. Initially intended to most recent 50 years, numerous parts have just outperformed. There are even parts that are around 100 years of age, and little is being done to supplant the matured parts. However the increase in electricity demand challenges the traditional power grid [14].

Due to the lack of energy resources and matured power grids, the downfall of electricity set in motion. As a result, numerous nations endeavor to build up a brilliant matrix to effectively use vitality assets with the steady and secure operation of the power lattice [15].

In section 2, an overview of The Smart Grid is presented with focus on DSM, section 3 presents the literature review of some of the closely related articles, section 4 presents the Motivation section for the article, sections 5 and 6 present the mathematical modelling for our proposed scheme, section 7 highlights the simulation results conducted whereas section 8 identifies the conclusion of the work as well as the future directions.

\section{The Smart Grid}

In Pakistan, the power conveyance framework is getting old and exhausted. Moreover, general population development has made the whole transmission framework abused and delicate. In recent years, many challenges have been encountered in electrical energy grids, which include global warming, increasing cultural conservation, the quest for energy security, and strict power reliability and quality requirements of the digital age [16].

\subsection{Derivation of DSM}

In order to achieve energy balancing or additional services, DSM is a way to take advantage of demand elasticity. The new opportunities offered by SG technologies, become an increasing issue for electrical systems and hence such flexibilities can be an effective way of minimizing peak electricity demand. Such opportunities could permit to keep away from using expensive power plants, with high variant costs along with essential air emissions [17]. Flexibilities will be crucial to ensure the network reliability, with an increasing part of fluctuating renewable production sources. Therefore, DSM could offer significant environmental, economical, and reliability benefits. The inspiration driving the implementation of DSM is clearly unique for the different gatherings included. Therefore for utility companies, the reduction or shift of a customer's energy demand could mean avoiding or delaying building additional generating ability. Taking clients into consideration, DSM facilitates them by decreasing electricity charge by effective as well as preservation techniques. On account of modern clients, it will result in decreased creation expenditures and an enhanced focused item. For residential clients it implies getting spare cash being utilized on rest of the family unit items. 
Utilities could consequently be considered as the main thrusts of DSM usage, whereas the electricity clients ought to likewise be provoked in utilizing vitality more effectively, afterward decreasing their vitality request and along these lines their vitality costs. Customers may likewise have the capacity to exploit any extraordinary impetuses offered by service organizations, and may take an interest in programs offered by the utilities (and perhaps upheld by government). Further improvement in cooperation to client satisfaction as well as DSM could very well be accomplished through establishing Distributed Energy Storage (DES), along with Distributed Energy Generation (DEG), as well as Distributed Energy Generation and Storage (DEGS) systems [18, 19].

DSM endeavors into two primary classifications:

- Reduction in cost in addition to environmental intensions

- Network in addition to authenticity intentions

\subsection{Scheduling of Appliances}

Scheduling is actually a technique through which an effort that is specified by some way is allocated to resources that fulfills the task. The thing is if we want to be productive in accomplishing our tasks, we should cuddle the supremacy of scheduling. By considering the cost saving factor for household in case of DSM, it is accomplished through appliances' optimal scheduling. Moreover, electricity bills are also reduces if maximum load is scheduled during low price. Due to proper scheduling not only electric bill is reduced but peak load is also reduced.

So as to pass up peak demands, the home appliances must be scheduled for the duration of low price periods. Such scheduling of home appliances results in sustaining the comfort level of users via coordination among consumers along with Home Energy Management System (HEMS) as well as helps in reducing the electricity bills. In short, the main purpose of scheduling the household appliances is to deal with the power consumption patterns, which results in reduction of energy cost.

\section{Literature Review}

In this section, related work done by different researchers on smart grid, DSM and scheduling, is presented.

In [20], the authors discovered a basic scheme to get a near optimal distribution setting for contribution tariffs. This scheme allows DSM originators to adjust the system headed to users' suitability which leads to a fewer regular consumption schedule adjustment, in the cost of system performance. Additionally, users do not require disclosing their comprehensive consumption schedules to conserve their confidentiality. Experiments showed the impact of the herding effect and estimate the effectiveness of the projected solution which demonstrates price equality for users.

The authors in [21] suggested a model of consumption known as cost efficiency as the measurement of consumption effectiveness. The authors designed a residential load scheduling algorithm to increase the cost efficiency of residential consumption by using the 
advanced Fractional Programming (FP) tools. The distributed energy resources (DERs) are also considered in the algorithm design and enhancement. The proposed scheduling algorithm is capable of resourcefully enhance the economic efficiency of the residential consumption, which facilitate the end user to accumulate its overheads although entirely handle the consumed power. The proposed cost efficiency metric by the authors did not address the consumption strategy with adjustable pricing system. In order to handle the slot between demand and supply, the consumer load should be scheduled by giving inducements to consumers.

In [22], the authors reflected a situation where numerous users collaborate to perform load demand scheduling so as to reduce the electricity production expenditure. A globally optimal solution can be accomplished with the help of a central controller in the grid but it cannot always be sufficient as a result, the authors proposed a distributed load demand scheduling algorithm where every consumer schedules his individual job consist of limited information given by other consumers. The presented algorithm was led by almost every end user independently, whereas they have not considered the scenario of multiple cooperative end users; since it may not always be feasible due to high communication requirement and hardware overhead. Similarly, the mentioned algorithm for scheduling, is considered to be fast and is capable of achieving almost optimal outcomes but results in performance decline.

In [23], the authors suggested a novel scheme of energy scheduling within SGs. The scheme enhances the process of numerous factors including battery storage, portable, as well as regulatory loads. Reduction in cost is the objective of such scheduling problem. Such reduction is accomplished through changing load necessities to most favorable time slots along with handling charge/discharging method for battery system of storage through favorable time slots. Simulations have carried out on regular distribution method. Results demonstrated the considerable minimization through scheduling using DSM. The MINLP objective function related to problem is described through:

$$
\min _{x} \frac{\Delta t}{60} *\left(\sum_{t \in T} C_{\operatorname{grid}(t)} * P_{\operatorname{Grid}(t)}+C_{a d j(t)} \sum_{i \in J} \sum_{l \in L}\left(P_{\operatorname{adj0}(i, t, l)}-P_{a d j(i, t, l}\right)\right)
$$

The authors need to consider a real-time voltage control method for Day-ahead Optimal Scheduling, to provide steady DC and AC bus voltages and ensure enhanced performance of DSM in smart grid. Due to day-ahead energy management approach the uncoordinated charging and discharging of batteries results in discomfort for consumers.

The researchers in [24] measured Time of use tariff (ToU) to relatively calculate the performance of the heuristic algorithms including bacterial foraging algorithm (BFA) and harmony search algorithm (HSA). A hybridization of BFA and HSA (HBH) is also suggested. These three heuristic approaches are used to evaluate the efficiency parameters such as electricity utilization cost and PAR. The main objectives of this paper are to reduce electricity utilization cost, minimize PAR, and to provide more comfort to users. ToU energy cost tariffs are used to determine electricity utilization cost and PAR. Control factors and categorization of appliances are held similar to relatively examine the performance of all contributing algorithms. Simulation outcomes authenticate that suggested method efficiently achieved preferred results while considering the consumer satisfaction. Although the presented scheme efficiently obtained the trade-off for the purpose of optimally managing 
electricity load in order to minimize cost, and since there is an exchange among cost of consuming electricity with satisfaction level of consumer.

The researchers in [25] considered load scheduling issue of electricity in a residence by classifying several appliances into five sets considering their different energy consumption and operation features, and present mathematical models for them. The authors proposed an electricity load scheduling algorithm for these appliance models that handle the operation time and energy consumption level of every appliance that adapted time-of-use rating to raise the efficiency and budget restriction of the residence. The authors only considered demand response problems for both elastic and inelastic appliances in a single residence without considering interactions among multiple residences as in the practical grid model.

\section{Motivation}

Load shedding is one of the major problems of our country which we are facing from the last few years due to electricity shortage. At present electricity short fall exceed 6000 MWs. As load shedding becomes a usual reality in the present situation of our country, so in consideration to the peak hours provided by service providers, we also have to consider the load shedding schedule given by service providers.

Energy Consumption Controlling (ECC) units, which are actually the decision making center for scheduling the throttleable and essential appliances. By considering the alternate power source and scheduling, heavy loads are shifted towards alternate resources in peakhours. Peak demand of appliances will be minimized through controlling essential electrical devices. As a result, cost of electricity for consumers will be considerably reduced. We want to evaluate our scheme which is Residential Power Scheduling \& Modelling for Demand Side Management (RPSMDSM) in terms of those appliances, which will prove to be a milestone in practical research.

Focus on one aspect considering DSM cannot oversea the reduction of gap between power demand and customer supply, which eventually leads to the issue of load shedding. Load shedding is one of the major problems of our country. Both domestic and commercial users have been badly affected due to this hitch. Presently, short fall exceeds 6000 MWs, with urban zones facing 12 hours and rural zones up to 16 hours of load shedding. As load shedding becomes a usual reality in the present situation of our country, so in consideration to the peak hours provided by service providers, we also have to consider the load shedding schedule given by service providers. The presented work is focused on two criteria:

i. Selection of appliances in Peak Hours of utility.

ii. Modelling of scheduling of selected appliances.

Hence, we have proposed a scheduling scheme that is based on first criteria, in which those appliances are selected, that needs to be Turned-On during peak hours consuming minimum energy. In the second criteria we have considered the electricity availability and its day-to-day schedule, and according to literature study that is conducted, we have come to know that such a research does not exist. We want to evaluate our modelling in terms of these appliances, which will be an important aspect in our research. Suggested method is aimed to reduce the electricity charges of the consumer by shifting the appliances activities from peak to off-peak hours. 


\section{Key Contributions:}

- The main purpose of presented scheme is to facilitate the consumer through satisfactory decline in the electricity bills, by means of transferring the household appliances process from high electricity consumption periods to low electricity consumption hours.

- $\quad$ At any moment, user may switch ON any appliance, irrespective of the peak hours concern and the consumer then received the convenient start time, suggested by the ECC unit.

\section{Residential Power Scheduling and Modelling for DSM (RPSMDSM)}

The increase in the economic growth as well as development of a country, electrical energy is rated as one of the major factor. Unfortunately, in Pakistan, the supply of electricity is less than the demand for electricity, which results in the gap between demand and supply, and the country start facing energy crises, in terms of severe electric power short fall and outages. As a result, it has slowed down the economic growth of Pakistan, and start affecting the lives of people in all sectors.

The researchers in papers [2], [17], and [24] have addressed DSM with focus on achieving load control of devices using scheduling. But they have not addressed the gap between demand and supply. Neither have they addressed load shedding mechanism. Similarly the authors in [4], [8] and [25] have addressed load scheduling mechanisms to some extents, but not considered the DSM. Considering both these aspects, we want to have a mechanism in which both of these issues can be addressed, as both of them are fully dependent on each other.

Load shedding is one of the major problems of our country which we are facing from the last few years due to electricity shortage. At present electricity short fall exceed 6000 MWs. As load shedding becomes a usual reality in the present situation of our country, so in consideration to the peak hours provided by service providers, we also have to consider the load shedding schedule given by service providers.

Energy Consumption Controlling (ECC) units, which are actually the decision making center for scheduling the throttleable and essential appliances. By considering the alternate power source and scheduling, heavy loads are shifted towards alternate resources in peakhours. Peak demand of appliances will be minimized through controlling essential electrical devices. As a result, cost of electricity for consumers will be considerably reduced. We want to evaluate our modelling in terms of these appliances, which will prove to be a milestone in practical research.

\subsection{Methodology}

To put into practice, residential power scheduling for DSM, and be forced to contend with load shedding, as well as to assist DSM for upcoming SG, the flowchart for the proposed scheme is shown in Fig. 4. Suggested method is aimed to reduce the electricity charges of the consumer by shifting the appliances activities from peak to off-peak hours.

To schedule home electric devices optimally, decision making centre, ECC units is used. Such decision making centre offers bidirectional communication through LAN and contact among users, and suggests likely schedule for almost every appliances. As mentioned, main purpose of the presented scheme is to facilitate the consumer through satisfactory decline in 
the electricity bills, by means of transferring the household appliances process from high electricity consumption periods to low electricity consumption hours. At any moment, user may switch ON any appliance, irrespective of the peak hours concern and the consumer then received the convenient start time, suggested by the ECC unit.

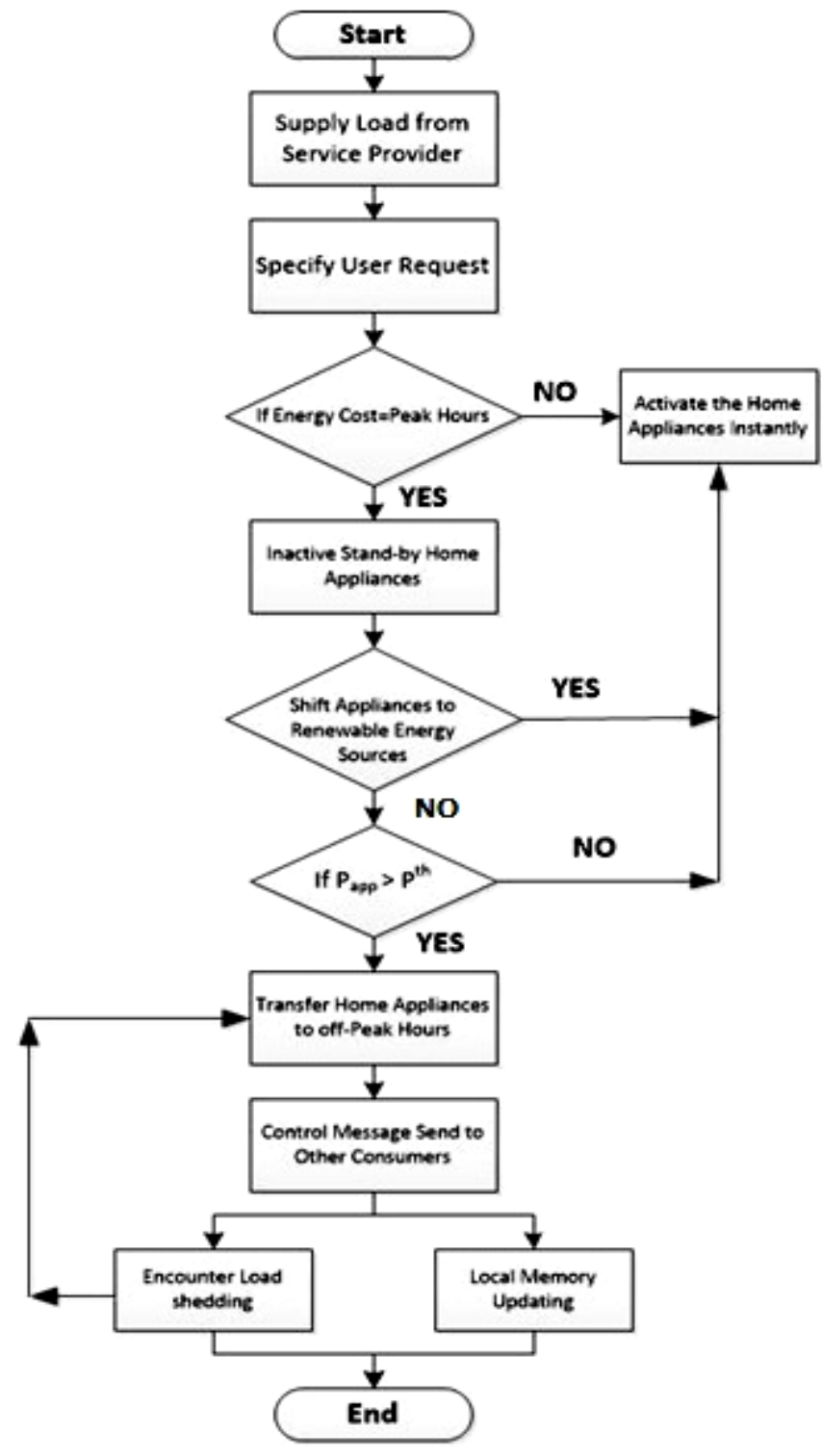

Fig. 4. Flowchart for RPSMDSM scheme

The flowchart of the proposed scheme goes through the following steps:

Step-1: After a load is supplied from the service provider the $\boldsymbol{n}_{\boldsymbol{t} \boldsymbol{h}}$ user turns on their $\boldsymbol{i}_{\boldsymbol{t h}}$ home appliances. Such a request for $\boldsymbol{i}_{\boldsymbol{t} h}$ appliance by $\boldsymbol{n}_{\boldsymbol{t} \boldsymbol{h}}$ user is generated randomly. Since, the request for an appliance from the consumer is not turned-ON instantly; rather it is forwarded to ECC. 
Step-2: Once the request is received by ECC unit, which is sent by the user for the appliance, first of all, highest electricity hours status should be checked. After the false condition, means the Energy Cost is not equal to Peak hours, then appliance " $\mathrm{i}$ " is switched ON instantly. Otherwise the scheme goes through the next step.

Step-3: During peak hours, stand-by electrical devices should be checked by ECC decision maker, to made them inactive, regardless of user desires to made them active. That is, when the energy cost meets the peak hours condition, and save a significant amount of energy.

Step-4: During highest rates of energy, decision making unit inspect the status of an electronic gadget in terms of load, which is to be turned-on. Or else by applying the delay factor, load become coped through such waiting condition. The nature of home appliance in terms of load is either transferrable, like washing machine, clothes dryer, or nontransferrable like television.

Step-5: Corresponding electronic gadget unit price is read by ECC, when there is highest ratings situation of transferrable load, and then such status be matched up to predetermined threshold condition, which is $\boldsymbol{P}_{\boldsymbol{m a x}}$. Instantly, the appliance become active in situations, when all $\boldsymbol{P}_{\text {app }} \leq \boldsymbol{P}_{\max }$. If the fixed threshold value, which is $\boldsymbol{P}_{\max }$ is greater than the power ratings of the $\boldsymbol{i}_{\boldsymbol{t}}$ appliance, then without any delay, the appliance is switched ON instantly. Otherwise the scheme goes through the following step.

Step-6: If Energy cost reaches to peak hours that is shiftable appliance having higher rating as compared to the predetermined range, then appliance's usage switched to off-hours. A delay factor is also introduced, for almost every appliance usage. A delay $\boldsymbol{d}_{\boldsymbol{i}}$ which is equivalent to the difference of the requested start time and scheduled time that has been suggested by ECC unit. Such a delay is contrary wise related with user's ease level. Instantly, appliance become active, if $\boldsymbol{d}_{\boldsymbol{i}}$ is greater than $\boldsymbol{D}_{\max }$ or else the operation cycle is shifted for $\boldsymbol{i}_{\boldsymbol{t}}$ appliance. Such type of shifting facilitates the user in dropping max out demand, therefore results in reducing the overall monthly bill of end user.

Step-7: Once appliances are scheduled by the ECC upon each request, a control message is send to consumer to schedule other electrical devices accordingly.

Step-8: Memory should be updated by consumer in case, when someone else sent the control message.

Step-9: In order to encounter load shedding, home appliances are transfer to off-peaks hours which will provide a turndown in power consumption.

The purpose our scheme is reducing the consumer electricity bill and minimizing wastage of energy caused through waiting state appliances. Normally, standby situation is actually that power consumption, when the appliance is switched off or the appliance is not functioning. It has been reported that standby devices contribute to electricity wastage, and such standby appliances, consuming $10 \%$ of electricity. Therefore it becomes necessary to hook up wastage caused by such electricity gadgets for the duration of scheduling home appliances for empowering DSM.

\section{Modelling for RPSMDSM}

The suppliers of electrical energy are trying to restructure the schedules of electrical energy in terms of generation, along with transmission through distribution, in order to fulfil energy demands from the customers. One of the solutions to satisfy the energy needs is the transformation of conventional grid into an advanced information and communication technologies smart grid. For energy management, the DSM mechanism of SG plays a vital 
role in the electricity market. Similarly, the scheduling of electrical home appliances in our lives is quite undeniable, and understood to minimize the PAR and make life simpler. Now a day's millions of people depend upon different types of electrical appliances around the world.

\subsection{Modeling Parameters}

The simulation parameters defined for the modelling and results, on behalf of which various appliances' optimal schedules have been generated, are mentioned in Table 1.

Table 1. Simulation Parameters for Modelling and Results

\begin{tabular}{|c|c|c|}
\hline S.No & Parameters & Values \\
\hline 1 & Hours of Applications & $12 / 24$ \\
\hline 2 & Energy Price (EP) & Variant \\
\hline 3 & No. of Appliances Used & 14 \\
\hline 4 & Unit Price & As per day slot \\
\hline 5 & Population Size (POPZIZE) & 500 \\
\hline 6 & Maximum Generation (MAXGEN) & 0.9 \\
\hline 7 & Crossover Rate (PC) & 0.1 \\
\hline 8 & Mutation Rate (Pm) & \\
\hline
\end{tabular}

Since, we have considered fourteen appliances, for 24 hours as well as 12 hours of a day, 24 bit binary pattern (000110011110011000110000) and 12 bit binary pattern (000110011110) is generated where state 0 represents OFF and state 1 represents ON appliances. To obtain optimal patterns, same process repeats for each time slot, since electrical energy prices differ, which is based on user preferences as well as appliances energy demand.

\subsection{Appliances categorization}

Appliances can be classified in terms of energy consumption pattern along with operational behavior, which are shiftable, controllable, and non-shiftable.

\subsubsection{Shiftable Appliances}

Shiftable appliances (like Washing machines and dishwasher) usage could be moved to whichever time period, but when they are in operation, cannot be interrupted. That is, they cannot be stopped, once their operation is started, unless and until the time slot reaches zero. In the following equations, $\boldsymbol{T n} \boldsymbol{A}$ represents the total number of appliances. $\boldsymbol{A} \in$ $\boldsymbol{T n} \boldsymbol{A}_{\boldsymbol{s}}$ signifies the set of shiftable appliances in equation (2). Whereas Pow and $\boldsymbol{a v} \boldsymbol{A}(\boldsymbol{h})$ indicates the power rating of each appliance. In equation (3), two cases are highlighted as, 0 and 1, when the particular appliance is switched-OFF and switched-ON respectively. Shiftable appliances are also known as deferrable appliances. 


\subsubsection{Non-Shiftable Appliances}

Non-Shiftable appliances (including refrigerator, television, and phone), operational time and energy consumption pattern cannot be changed. These appliances are also known as base appliances. The set of non-shiftable appliances is represented by $\boldsymbol{A} \in \boldsymbol{T} \boldsymbol{n} \boldsymbol{A}_{\boldsymbol{n} \boldsymbol{s}}$ in equation (2).

\subsubsection{Controllable Appliances}

Unlike Shiftable appliances, which cannot be interrupted, Controllable appliances (like air condition, heating system, and lightning) can be interrupted. However, time of such machines when are in operation, unable to altered. $\operatorname{Tn} A_{c}$ symbolizes as the set of controllable appliances. Controllable appliances' cost is mentioned in equation (2). $\operatorname{Tn} A_{n s}$ symbolizes as the set of non-scheduled appliances. $T n A_{s}$ symbolizes as the set of scheduled appliances.

$$
\begin{aligned}
& A=\operatorname{Tn} A_{s}, \operatorname{Tn} A_{n s}, \operatorname{Tn} A_{c} \\
& \operatorname{avA}(h)= \begin{cases}0 ; & \text { if appliance a is turned }-O F F \\
1 ; & \text { if appliance a is turned }-O N\end{cases}
\end{aligned}
$$

PowA symbolizes as the net power consumed by all the controllable appliances. $a v A(h)$ symbolizes as the average time of controllable appliances operated in hours.

\subsection{System Model}

Table 2 shows the classification and power rating of each appliance and elaborates the structural design of our proposed scheme, in which 14 different appliances are considered. There are different power ratings for each appliance. To achieve the objective function, appliances are scheduled. HEM system is integrated between consumer and utility and bidirectional flow is presented in the scheme. Generally, in peak hours the rates of electricity are higher as compared to normal hours. Peak hours can be defined as, point in time periods, when load request arrives at highest rate. Therefore, appliances with heavy electricity consumption cannot be turned $\mathrm{ON}$ in peak electricity hours. In order to reduce the amount of electricity bills, ECC unit is integrated to provoke automation. Initially, electrical energy rates are forwarded to user. Taking such rates into consideration, ECC makes a decision for an appliance to be switched ON. Utility defines various electrical energy pricing signs like Real Time Pricing (RTP), and TOU.

Table 2. Parameters of Appliances Utility

\begin{tabular}{|c|c|c|c|c|c|}
\hline Appliance & $\begin{array}{c}\text { Types of } \\
\text { Appliances }\end{array}$ & $\begin{array}{c}\text { Power } \\
\text { Ratings } \\
\text { (watts) }\end{array}$ & $\begin{array}{c}\text { Kilo Watts } \\
\mathbf{( k W )}\end{array}$ & $\begin{array}{c}\text { LOT } \\
\text { (Hours } \\
\text { Consumption) }\end{array}$ & kWh/unit \\
\hline Cloth Dryer & Shiftable & $1800-5000$ & 1.8 & $1-2$ & 3.6 \\
\hline Dish Washer & Shiftable & $1200-2400$ & 1.8 & $4-5$ & 7.2 \\
\hline Washing Machine & Shiftable & $500-1300$ & 0.75 & $1-2$ & 1.5 \\
\hline
\end{tabular}




\begin{tabular}{|c|c|c|c|c|c|}
\hline Oven & Controllable & $1000-1500$ & 1.05 & $1-1.5$ & 1.575 \\
\hline Iron & Non-Shiftable & $800-2000$ & 1.1 & $4-5$ & 4.4 \\
\hline Vacuum Cleaner & Non-Shiftable & $1000-1500$ & 1 & $1-1.5$ & 1.5 \\
\hline Fan & Non-Shiftable & $55-100$ & 0.075 & $18-20$ & 1.35 \\
\hline Kettle & Controllable & $1200-3000$ & 1.8 & $1-1.5$ & 2.7 \\
\hline Toaster & Non-Shiftable & $900-1000$ & 0.9 & $1-1.5$ & 1.35 \\
\hline Rice Cooker & Controllable & $700-2000$ & 1.2 & $1-2$ & 2.4 \\
\hline Hair Dryer & Shiftable & $800-1800$ & 1.2 & $0.5-1$ & 1.2 \\
\hline Blender & Shiftable & $800-1200$ & 1 & $0.5-1$ & 1.0 \\
\hline Frying Pan & Non-Shiftable & $1200-2000$ & 1.5 & $1-1.5$ & 2.25 \\
\hline Coffee Maker & Controllable & $800-1500$ & 1 & $1.5-2$ & 2 \\
\hline
\end{tabular}

From the above table, it is clear that if an appliance, for example washing machine is used for 2 hours with an average 750 watts. Then in $\mathrm{kW}$ its value will be 0.75 . After that if we multiply the $\mathrm{kW}$ value with total hours used, then it will give $\mathrm{kWh}$, and in Pakistan $1 \mathrm{kWh}=$ 1 unit. So in our case washing machine is consuming 1.5 per day. Now if an appliance is used 8 to 10 times in a month, then we will simply multiply per day units consumed by an appliance with the total time used in a month, and that value will represent the total units consumed by an appliance in a month. At the end, we will multiply total units with unit price offered by an energy provider, which will give the electricity bill generated by that specific appliance.

\subsubsection{Energy Demand Optimization}

The energy consumption of 14 different appliances is considered by RPSMDSM scheme. As such electrical devices normally controlled by means of considering user presence. The exact energy consumption demand in a house is very hard to predict. Therefore, considering the real-time activities of residents is one of the solutions to overcome this problem, due to which energy consumption can be computed. In designing the interactive and dynamic energy management scheme, the energy consumption patterns uncertainty, which depends on different users' daily activities, may form difficulties.

For instance, whenever the resident is present in the room, the Fan must be switched ON. Whereas the Demand Response (DR) signal based scheduling techniques may results in energy wastage. In RPS-DSM, user dependent appliances $\boldsymbol{a} \in \mathbf{A}_{\boldsymbol{u d}}$ are made active, as well as overall cost for these appliances is calculated, during the ON time interval. Energy consumption for interactive schedulable appliances $\boldsymbol{a} \in \mathbf{A}_{i s}$ is computed in already decided schedules, which is normally placed via users. Although, to minimize the total electricity cost, appliances could be programmed for the period ofts $\in \mathbf{T}$. Washing machine and dish washer are kept in this type. Unschedulable appliances $\boldsymbol{a} \in \mathbf{A}_{\boldsymbol{u s}}$ like TV, music player, and is the last category, has fixed energy consumption, which are at any time can be turned-On by the user. 
We have considered $\boldsymbol{h} \in \boldsymbol{H}$ homes in RPS-DSM, having $\boldsymbol{A}$ appliances of different types, so that $\boldsymbol{A}=[1,2, \mathbf{3}, \ldots \ldots \ldots \ldots)$.In case of ours scenario, the Real Time Pricing (RTP) and TOU signals have been used and after that the total scheduling time horizon $\boldsymbol{T}_{\boldsymbol{s t h}}$ is split up into the same length time slots.

$$
T_{\text {sth }}=\left[t i_{1}, t i_{2}, t i_{3}, \ldots \ldots t i_{n}\right]
$$

where $\boldsymbol{t} \boldsymbol{i}_{\boldsymbol{n}}$ designates to 24 . It is the responsibility of ECC to decide the total energy consumption $\boldsymbol{T} \boldsymbol{E} \boldsymbol{c}$ of $\boldsymbol{A}$ appliances, as well as the starting and ending time intervals, indicated by $\boldsymbol{t} \boldsymbol{i}_{\boldsymbol{s}}$ and $\boldsymbol{t} \boldsymbol{i}_{\boldsymbol{e}}$ respectively. The energy consumption over a given sub-interval of time $\boldsymbol{t} \boldsymbol{i}_{\mathbf{1}}$ is assumed to be constant. For appliance $\boldsymbol{a} \in \mathbf{A}$, Energy consumption scheduling vector $\boldsymbol{E C} \boldsymbol{s} \boldsymbol{v}$ is specified by:

$$
E C s v=\left[e_{a}^{t i_{1}}, e_{a}^{t i_{2}}, e_{a}^{t i_{3}}, \ldots, e_{a}^{t i_{n}}\right]
$$

The energy consumption in KWh of appliance aatti $\mathbf{t}^{\text {th }}$ time slot is mentioned in equation (5). Each appliance $\mathbf{a}$ can be scheduled, since each appliance has a scheduling time interval, and is denoted by $\boldsymbol{t} \boldsymbol{i}_{\boldsymbol{s c h}} \in\left[\boldsymbol{t} \boldsymbol{i}_{\boldsymbol{s}}, \boldsymbol{t} \boldsymbol{i}_{\boldsymbol{f}}-\boldsymbol{t} \boldsymbol{i}_{\text {lot }}\right]$.

The energy consumption of appliance $\boldsymbol{a}$, which is symbolized as $\boldsymbol{E} \boldsymbol{C}$ is bounded between minimum, that is, $\left(\boldsymbol{E} \boldsymbol{C}_{\boldsymbol{a}}\right)^{\boldsymbol{m i n}}$ and maximum, which is $\left(\boldsymbol{E} \boldsymbol{C}_{\boldsymbol{a}}\right)^{\boldsymbol{m a x}}$ bounds, at the time when appliance $\boldsymbol{a}$ is switched-ON.

$$
E C_{(a, t i)}^{\min } \phi(\mathbf{a}, t i) \leq E C_{(a, t i)} \leq E C_{(a, t i)}^{\max } \phi(\mathbf{a}, t i)
$$

At time slot $\boldsymbol{t} \boldsymbol{i}$, the ON/OFF status of appliance $\boldsymbol{a}$ is denoted by $\boldsymbol{\phi}(\mathbf{a}, \boldsymbol{t} \boldsymbol{i})$. As compared to simple time-based models, the ON/OFF mechanism of appliance handles the scheduling process more practically. Like the ON/OFF mechanism is easy to mock-up, if during high price hours, user wants to stop any appliance.

$$
\phi(\mathbf{a}, t i)=\left\{\begin{array}{l}
0 ; \text { if appliance a is switched }-O F F \text { at time slot ti } \\
1 ; \text { if appliance } a \text { is switched }-O N \text { at time slot ti }
\end{array}\right.
$$

The energy which is consumed by $\boldsymbol{A}$ number of appliances at timet $\boldsymbol{i}$ can be calculated in the following equation as:

$$
T E C=\sum_{h=1}^{H} \sum_{t i=1}^{t i_{n}} \sum_{a=1}^{N} E C_{(t i, a)}^{H} \cdot \Phi_{(t i, a)}^{H}
$$

where $\boldsymbol{T} \boldsymbol{E} \boldsymbol{C}$ indicates the total energy consumption of $\boldsymbol{a}$ appliances during timeslot $\boldsymbol{t} \boldsymbol{i}$. Further presumption is that in time slot, every electrical device has highest energy usage limit $\boldsymbol{E} \boldsymbol{C}_{\boldsymbol{m a x}}^{\boldsymbol{t i}}$. As an instance, $3.4 \mathrm{kWh}$ of electricity used by washing machine during every hour, in such a way $\boldsymbol{E C}_{\boldsymbol{a}}^{\boldsymbol{t i}} \leq \boldsymbol{E} \boldsymbol{C}_{\boldsymbol{m a x}_{\boldsymbol{a}}}^{\boldsymbol{t}}$. Whereas $\boldsymbol{E} \boldsymbol{C}_{\boldsymbol{a}}^{\boldsymbol{t i}}$ highlights the energy consumed by appliance $\boldsymbol{a}$ at time slot $\boldsymbol{t} \boldsymbol{i}$. Furthermore, on all types of appliances, there is a total energy consumption limit as well in each time slot $\boldsymbol{t} \boldsymbol{i}_{\boldsymbol{n}}$, which can be computed in the following formula:

$$
\sum_{h=1}^{H} \sum_{t i=1}^{t i_{n}} \sum_{a=1}^{N} E C_{(t i, a)}^{H} \cdot \boldsymbol{\phi}_{(t i, a)}^{H} \leq \boldsymbol{\phi}_{(t i, a)}^{H}
$$


High peaks will be generated in case of violating the above mentioned constraints, and hence results in power grid damage. By satisfying the needs of energy demand during low price hours, the scheduling algorithms should track the constraint as well as electrical energy production cost. Once electricity consumption as well as capacity limit of the appliance has been described, time for the formulation of cost started. TOU along with RTP have been used, where prices of electricity differs during every time period $\boldsymbol{t} \boldsymbol{i}$ and symbolized as $\boldsymbol{Q}_{\boldsymbol{t} \boldsymbol{i}}$. For scheduling intervals, assumption has been made that all electricity unit prices $\boldsymbol{Q}_{\boldsymbol{t} i}$ are known to the Energy Management Controller (EMC) in advance. For all types of appliances, the total energy consumption cost $C_{T E C}$ is given as:

$C_{T E C}=\sum_{h=1}^{H} \sum_{t i=1}^{t i_{n}} \sum_{a=1}^{N} E C_{(t i, a)}^{H} \cdot \boldsymbol{\phi}_{(t i, a)}^{H}$

\subsubsection{Load Scheduling}

The key feature of our scheme is the reduction in energy consumption by considering energy prices, and human presence. By concerning the reduction in the bills generated through electricity as well as max out during cheap cost periods, appliances must be scheduled by taking into consideration the energy rates. For energy consumption minimization, the final optimization problem is given in the following equation:

$$
O=\min \sum_{h=1}^{H} \sum_{t i=1}^{t i_{n}} \sum_{a=1}^{N} E C_{(t i, a)}^{H} . \phi_{(t i, a)}^{H}
$$

such that:

$$
\begin{gathered}
0 \leq t i \leq T \\
t i_{s c h}=\left[t i_{s}, t i_{f}-t i_{l o t}\right] \\
E C_{t i} \leq t i \\
E C_{(a, t i)}^{\min } \phi(\mathbf{a}, t i) \leq E C_{(a, t i)} \leq E C_{(a, t i)}^{\max } \phi(\mathbf{a}, t i) \\
\phi=[0,1]
\end{gathered}
$$

First constraint (11a) indicates that $\boldsymbol{t} \boldsymbol{i}_{\boldsymbol{s}}$ and $\boldsymbol{t} \boldsymbol{i}_{\boldsymbol{f}}$ should be in between the total time limit $\mathbf{t i} \in$ T. Similarly, second constraint (11b) shows the total scheduling time horizon. Whereas the third constraint (11c) limits the total energy, not to exceed the available energy capacity which is consumed by almost all types of appliances. In case, when the status is ON, its energy consumption pursues constraint (11d). Finally, in the fifth constraint (11e), each appliance has two possible states, which are ON and OFF.

\subsubsection{PAR Reduction}

By setting the maximum energy load demand vector $(\boldsymbol{E C})_{t i, \boldsymbol{a}}$, The $\boldsymbol{a}^{\boldsymbol{t h}}$ appliance energy consumption on a daily basis in time slot $\boldsymbol{t} \boldsymbol{i}$ is mentioned in the following formula:

$$
E C=\sum_{t i=1}^{t i_{n}} \sum_{a=1}^{N} E C_{(t i, a)} \cdot \phi_{(t i, a)}
$$

In case of average load demand, we can formulate PAR as follows: 


$$
P A R=\frac{\max _{t i \epsilon t i_{n}} \sum_{a=1}^{N} E C_{(a)}}{\frac{1}{T} \sum_{a=1}^{N} E C_{(a)}}
$$

The problem of optimization in PAR reduction can be formulated in the following equation:

$$
O=\min P A R
$$

\section{Results and Discussions}

Results demonstrate the performance factor in RPSMDSM method by considering scheduled as well as unscheduled load, Real Time Pricing (RTP) and energy consumption requirements of home appliances. Results for Total Cost as well as minimization in PAR are revealed on behalf of diverse Operation Time Intervals (OTIs).

To schedule the home appliances, Energy Management Controller (EMC) is installed inside a home. We have considered fourteen appliances, which are controlled and operated automatically, and are used in almost every home. It is understood that every appliance has different starting time bounds as well as lengths of operation time. In our scheme, we have considered the scheduling time horizon $\mathrm{T}_{\text {sth }}=24$, and $\mathrm{T}_{\text {sth }}=12$ to compute total electricity invoice on behalf of 24 hours as well as for 12 hours a day respectively, and on the basis of that, the consumer can solve the optimization problem. During 24h, as well as in $12 \mathrm{~h}$ it is possible that the residential user could use some of the home appliances more than once.

\subsection{Performance Parameters: Discussion}

\subsubsection{Cost}

Main objective of the implemented RPSMDSM scheme is to reduce the electricity cost of home appliances, which can be achieved through shifting the appliance electricity load as of peak energy consumption periods to low energy consumption hours, which will results in the reduction of electricity bill. Fig. 5 has demonstrated the cost by considering different Operation Time. Fig.s 5 (a) and (b) indicate the overall net cost using Real-time Pricing respectively for 24 hours and 12 hours in respect to scheduled and unscheduled appliances utility.

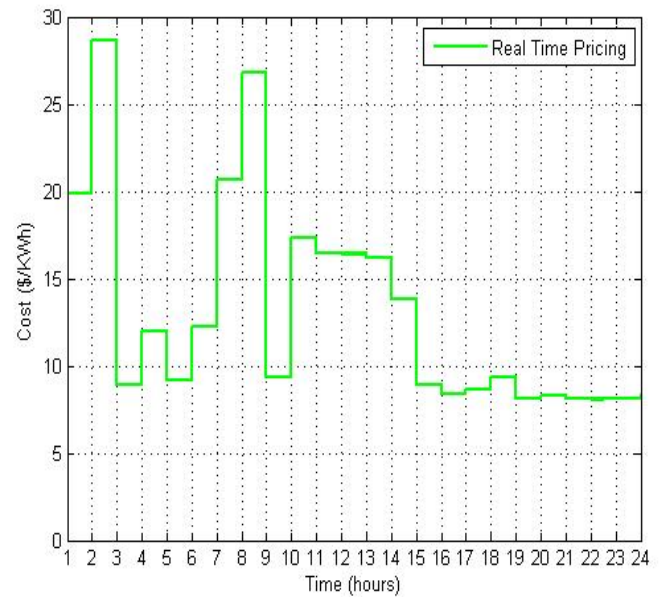

Fig. 5 (a). Cost using RTP for $24 \mathrm{hrs}$

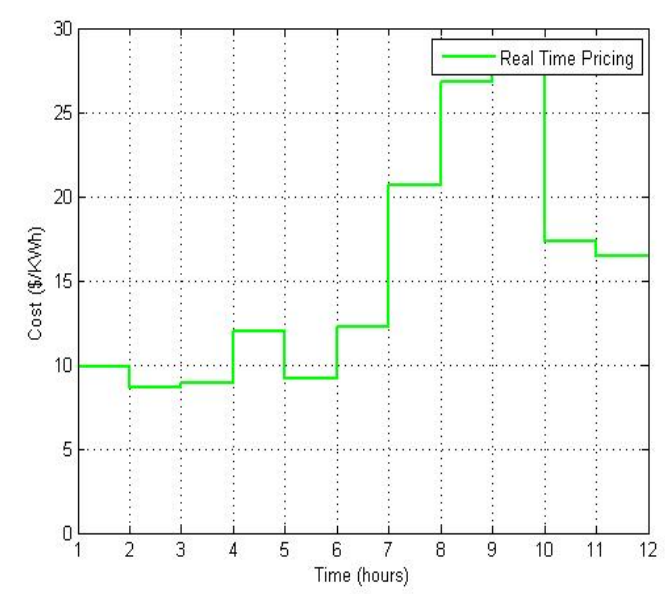

Fig. 5 (b). Cost using RTP for 12 hrs 
Intervals (OTIs) to assess price factor of RPSMDSM scheme. For each time slot (1-24) as well as (1-12), cost is specified for the unscheduled and scheduled states.

\subsubsection{Energy Consumption}

The energy consumption ( $\mathrm{kWh}$ ) pattern of users for scheduled and unscheduled load in 24 hours as well as for 12 hours with OTI is shown in Fig. 6. Fig.s 6 (a) and (b) indicate the overall energy consumption respectively for 24 hours and 12 hours in respect to scheduled and unscheduled appliances utility. When the appliances are unscheduled, load is increased in the peak hours of the day. Whereas, according to the RPSMDSM scheme, when we scheduled the appliances, load is decreased and evenly distribute over the entire day. As compared to unscheduled load, the RPSMDSM scheme represents the reduction in similar pattern of energy consumption in case of scheduled load. In the presented scheme, ECC unit scheduled the energy utilization more efficiently, and hence results in the peak load minimization.

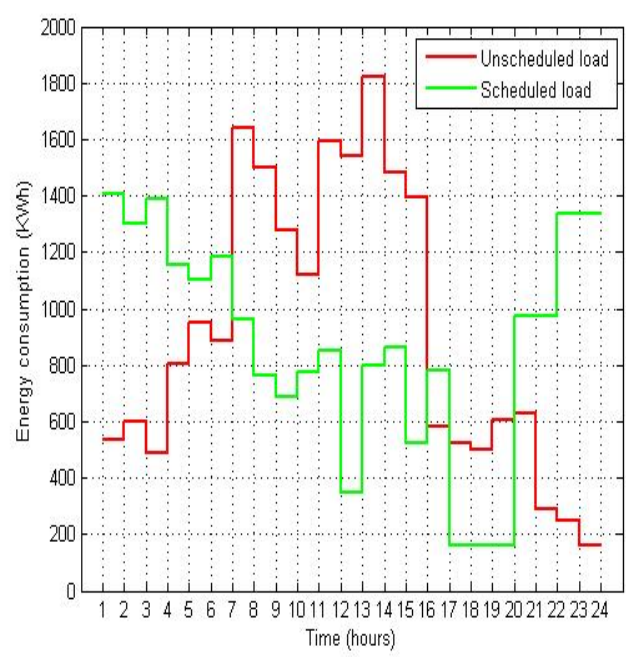

Fig. 6 (a). Energy Consumption in 24hrs

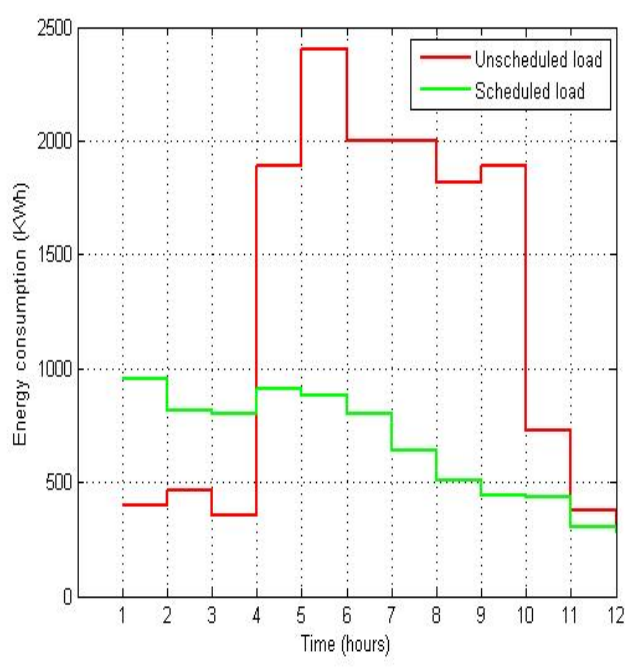

Fig. 6 (b). Energy Consumption in $12 \mathrm{hrs}$

\subsubsection{Total Cost}

To maintain coordination between electrical energy charges along with consumption prototype, appliances are scheduled during specific time period. Fig.s 7 (a) and (b) indicate the overall net cost respectively for 24 hours and 12 hours in respect to scheduled and unscheduled appliances utility. Figs. 7 clearly observed the presence of peaks, when the appliances are unscheduled, which demonstrated with the aim of high price rates in such time periods. Although, these max outs are reduced in scheduled case. However, a variation in the total cost pattern is minor. Scheduled load of appliances has minimal cost, which means that RPSMDSM scheme could help in reducing the electricity bill. 


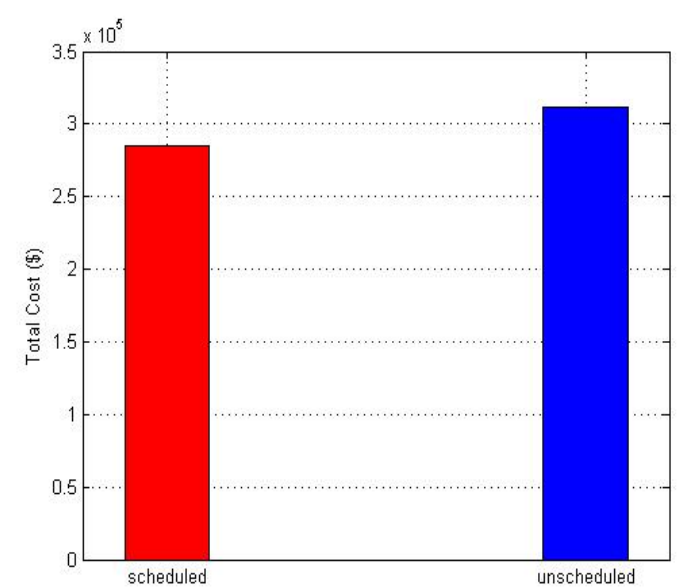

Fig. 7 (a). Net Cost Comparison for 24hrs

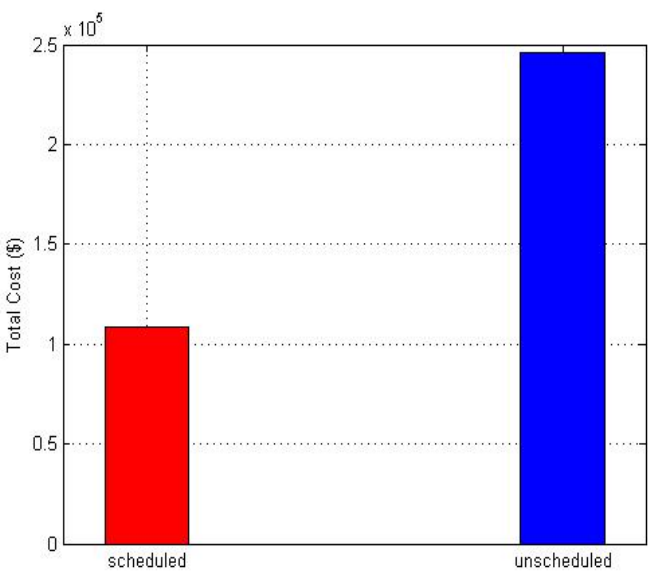

Fig. 7 (b). Net Cost Comparison for 12hrs

\section{Conclusion}

To keep up the stability of the power grid, the conventional network is transformed into a brilliant lattice, which is the smart grid. In a brilliant lattice network, DSM plays a vital role in permitting buyers, boosted by utilities, to deal with their vitality utilization. Distinctive analysts have dealt with DSM utilizing power stockpiles later on future smart grid. Essentially, the power stockpiling has been a concern of just the energy suppliers utilizing extensive synthetic batteries to store vitality from alternating sustainable power sources.

DSM is considered to be a key component to keep up harmony among demands for electricity as well the supply of the electricity. DSM assists with the steady process of electric grid in addition to helps in reducing electric charges of the grid for clients. It should be possible through moving utilization to off-crest hours and therefore diminishing the peak to-average proportion (PAR) of the electricity framework.

To reduce the expense of electricity usage and PAR, for the residential sector, the scheme of RPSMDSM scheme has been proposed. The RPSMDSM scheme performance is assessed by actualizing it on a residential unit with numerous appliances having diverse pricing schemes and portrayed the impact of appliance scheduling. During peak hours of electricity, the RPSMDSM is capable to persuade less power consumption and accomplish productivity in load management. It has been observed that RPSMDSM scheme helps in scheduling the electricity loads from peak price to off-peak price hours. As a result, minimizations in electricity cost as well as PAR are accomplished with sensible waiting time.

In the economic development of the country, the electricity is considered as one of the essential service. In all sectors of the country, the demand for electrical energy consumption is directly proportional to increase in population. Unfortunately, the supply of electricity generated in Pakistan is less than the demand for electricity, which results in the gap between demand and supply. Hence the country starts confronting extreme electric power deficiencies in terms of load shedding and blackouts, which has a huge impact on not only slowing down the economic growth, but also the lives of individuals in all sectors of the country. 
Due to the predominant crises of electrical energy since long in this way, generally the country and PESCO specifically, is being confronting, scheduled and un-scheduled (because of framework imperative) electrical power shortage (load shedding) on a large scale for indefinite time period, that must be taken to fulfill the breach among supply with respect to demand of electrical power, to avoid aggregate electricity outage and breakdown, so that to make sure the reliability and power network system stability. Therefore, the RPSMDSM also considered power flow control information as well as scheduled different types of appliances operation, which helps to avoid load shedding and also save electrical power network system to keep away from load shedding, and spare power arrange framework.

Results demonstrated that the presented demand side energy consumption scheduling scheme offered a valuable approach in minimizing the electrical energy costs, along with minimization in consumption of energy, while at the same time taking into consideration consumer preferences, PAR constraints as well as issues of load shedding. From the outcomes, it is inferred that RPSMDSM beats the current methods.

\subsection{Future Work}

In our research the results can be pulled out in the variety of forms. Like multiple heuristic optimization techniques for the purpose of reduction in electricity cost and PAR can be explored. Our research work could be expanded for an entire residential unit, where advanced forecasting techniques for the entire load demand estimation will be used. One more future research route in support of scheduling home electrical devices can be cloud concept instead of using an EMC. In the same way, consumers be capable of trading stored energy with energy supplier during few circumstances, since our scheme does not enable consumers to trade energy back to the energy supplier. Similarly, by considering the presented technique, research work could be expanded for generation of renewable sources of energy. Consumers can adequately utilize these resources to lessen electricity expenses by utilizing batteries and renewable energy resources.

\section{References}

[1] Fang, Xi, Satyajayant Misra, GuoliangXue, and Dejun Yang, "Smart grid-The new and improved power grid: A survey,” IEEE communications surveys \& tutorials, 14, no. 4, 944980, 2011. Article (CrossRef Link)

[2] Liu, Yi, Chau Yuen, Shisheng Huang, Naveed Ul Hassan, Xiumin Wang, and Shengli Xie, "Peak-to-average ratio constrained demand-side management with consumer's preference in residential smart grid,” IEEE Journal of Selected Topics in Signal Processing, 8, no. 6, 10841097, 2014. Article (CrossRef Link)

[3] Touzene, Abderezak, Sultan Al Yahyai, and Amar Oukil, "Smart grid resources optimisation using service oriented middleware,” IJCAT, 59, no. 1, 53-63, 2019. Article (CrossRef Link)

[4] Said, Gul Nabi, Sheeraz Ahmed, Kashif Ali Awan, and Amjad Khattak, "Electrical energy regulation and load management for addressing power crisis in Pakistan,” in Proc. of 2nd International Multi-Disciplinary Conference, vol. 19, p. 20. 2016. 
[5] Samadi, Pedram, Hamed Mohsenian-Rad, Robert Schober, and Vincent WS Wong, "Advanced demand side management for the future smart grid using mechanism design,” IEEE Transactions on Smart Grid, 3, no. 3, 1170-1180, 2012.

Article (CrossRef Link)

[6] Zahoor, Saman, Nadeem Javaid, Asif Khan, Bibi Ruqia, Fatima J. Muhammad, and Maida Zahid, "A cloud-fog-based smart grid model for efficient resource utilization," in Proc. of 2018 14th International Wireless Communications \& Mobile Computing Conference (IWCMC), IEEE, pp. 1154-1160, 2018. Article (CrossRef Link)

[7] Pehnt, Martin, "Dynamic life cycle assessment (LCA) of renewable energy technologies,” Renewable energy, 31, no. 1, 55-71, 2006. Article (CrossRef Link)

[8] Samadi, Pedram, Vincent WS Wong, and Robert Schober, "Load scheduling and power trading in systems with high penetration of renewable energy resources,” IEEE Transactions on Smart Grid, 7, no. 4, 1802-1812, 2015. Article (CrossRef Link)

[9] Abdeshahian, Peyman, Jeng Shiun Lim, Wai Shin Ho, Haslenda Hashim, and Chew Tin Lee, "Potential of biogas production from farm animal waste in Malaysia," Renewable and Sustainable Energy Reviews, 60, 714-723, 2016. Article (CrossRef Link)

[10] Ullah, M. N., Nadeem Javaid, I. Khan, Anzar Mahmood, and M. U. Farooq, "Residential energy consumption controlling techniques to enable autonomous demand side management in future smart grid communications," in Proc. of 2013 Eighth International Conference on Broadband and Wireless Computing, Communication and Applications, IEEE, pp. 545-550, 2013. Article (CrossRef Link)

[11] Naqi Shah, Sadia, and Abdul Qayyum, “Analyse Risk-Return Paradox: Evidence from Electricity Sector of Pakistan,” 117-138, 2016.

[12] Wu, Felix F., Pravin P. Varaiya, and Ron SY Hui, "Smart grids with intelligent periphery: An architecture for the energy internet,” Engineering, 1, no. 4, 436-446, 2015.

Article (CrossRef Link)

[13] Kim, Sungwook, "An adaptive smart grid management scheme based on the coopetition game model,” ETRI journal, 36, no. 1, 80-88, 2014. Article (CrossRef Link)

[14] Longe, Omowunmi Mary, and Khmaies Ouahada, "Mitigating Household Energy Poverty through Energy Expenditure Affordability Algorithm in a Smart Grid,” Energies, 11, no. 4, 947, 2018. Article (CrossRef Link)

[15] Roh, Hee-Tae, and Jang-Won Lee, "Residential demand response scheduling with multiclass appliances in the smart grid,” IEEE Transactions on Smart Grid, 7, no. 1, 94-104, 2015. Article (CrossRef Link)

[16] A. Ghasempour, "Internet of Things in Smart Grid: Architecture, Applications, Services, Key Technologies, and Challenges,” Inventions journal, vol. 4, no. 1, pp. 1-12, 2019.

Article (CrossRef Link)

[17] Mahmood, Danish, Nadeem Javaid, Sheraz Ahmed, Imran Ahmed, Iftikhar Azim Niaz, Wadood Abdul, and Sanaa Ghouzali, "Orchestrating an effective formulation to investigate the impact of EMSs (energy management systems) for residential units prior to installation,” Energies, 10, no. 3, 335, 2017. Article (CrossRef Link)

[18] A. Ghasempour, "Optimized scalable decentralized hybrid advanced metering infrastructure for smart,” in Proc. of IEEE Int. Conf. on Smart Grid Commun., Miami, pp. 223-8, 2015. Article (CrossRef Link)

[19] Longe, O. M., K. Ouahada, H. C. Ferreira, and S. Rimer, "Consumer preference electricity usage plan for demand side management in the smart grid," SAIEE Africa Research Journal, 108, no. 4, 174-183, 2017. Article (CrossRef Link) 
[20] Wijaya, Tri Kurniawan, Thanasis G. Papaioannou, Xin Liu, and Karl Aberer, "Effective consumption scheduling for demand-side management in the smart grid using non-uniform participation rate,” in Proc. of Sustainable Internet and ICT for Sustainability (SustainIT), IEEE, pp. 1-8, 2013. Article (CrossRef Link)

[21] Hussain, Hafiz Majid, NadeemJavaid, SohailIqbal, QadeerUlHasan, Khursheed Aurangzeb, and MusaedAlhussein, "An Efficient Demand Side Management System with a New Optimized Home Energy Management Controller in Smart Grid,” Energies, 11, no. 1, 190, 2018. Article (CrossRef Link)

[22] Mahmood, Anzar, M. N. Ullah, S. Razzaq, Abdul Basit, U. Mustafa, M. Naeem, and NadeemJavaid, "A new scheme for demand side management in future smart grid networks,” Procedia Computer Science, 32, 477-484, 2014. Article (CrossRef Link)

[23] Shaaban, M. F., A. H. Osman, and M. S. Hassan, "Day-ahead Optimal Scheduling for Demand Side Management in Smart Grids,” in Proc. of Modelling Symposium (EMS), European, IEEE, pp. 124-129, 2016. Article (CrossRef Link)

[24] Nguyen, Hung Khanh, Ju Bin Song, and Zhu Han, "Demand side management to reduce peak-to-average ratio using game theory in smart grid," in Proc. of Computer Communications Workshops (INFOCOM WKSHPS), 2012 IEEE Conference on, pp. 91-96, 2012. Article (CrossRef Link)

[25] Rasheed, Muhammad Babar, Nadeem Javaid, Ashfaq Ahmad, Mohsin Jamil, Zahoor Ali Khan, Umar Qasim, and Nabil Alrajeh, "Energy optimization in smart homes using customer preference and dynamic pricing,” Energies, 9, no. 8, 593, 2016. Article (CrossRef Link)

[26] Gaur, Gaurav, Nishtha Mehta, RintuKhanna, and SandeepKaur, "Demand side management in a smart grid environment,” in Proc. of Smart Grid and Smart Cities (ICSGSC), 2017 IEEE International Conference on, IEEE, pp. 227-231, 2017. Article (CrossRef Link)

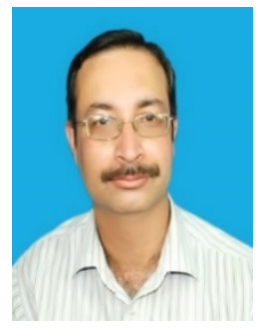

Dr. Sheeraz Ahmed did his graduation in Electrical Engineering (Communication Group) from University of Engineering and Technology, Peshawar, Pakistan with Honors in 1997. He then did his Masters in Mathematics from University of Peshawar in 1999. In 2006, he got enrolled in MSCS program in City University of Science and Technology, Peshawar and completed his MS program with major in Computer Networks. He then got enrolled in $\mathrm{PhD}$ program in Electrical Engineering in COMSATS Islamabad in Spring 2012 and completed his Doctoral degree in Spring 2015. His thesis title was "Towards Cooperative Routing in Underwater and Body Area Wireless Sensor Networks”. Dr. Sheeraz has been engaged in serving various universities of Peshawar as an active researcher. Currently he is serving as Full Professor in the department of Computer Science, Iqra National University, Peshawar. Till date, he has 160 plus publications to his credit with more than 35 IF journals, 42 non-IF journals and rest IEEE conferences. He has the honor to be the first researcher to establish a Research Academy in Pakistan by the name of Career Dynamics Research Centre. His research interest areas include Underwater Sensor Networks, Body Area Networks, Vehicular Adhoc Networks, Flying Adhoc Networks, Smart Homes, Smart Grid etc. 


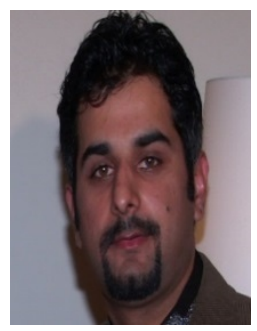

Ali Raza received the M.Sc. degree in Computer Science, from University of Peshawar, Pakistan, in 2004. In 2018, he received the MS degree in Computer Science, with specialization in Software Engineering, from CECOS University of IT \& Emerging Sciences Peshawar, Pakistan. Since 2004 and till date, he has been serving his services in the field of teaching, and currently, working as an Assistant Professor in the Department of Computer Science, at Edwardes College Peshawar, Pakistan. His research focuses on Smart Homes, along with Smart Grids. His major research interests include, Residential Power Scheduling, scheduling of home appliances, and Demand Side Management techniques in Smart Grids.

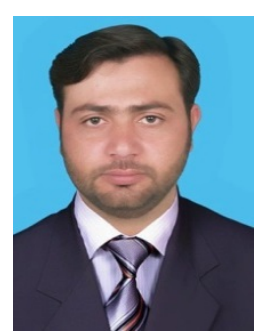

Dr. Shahryar Shafique Qurashi is serving as Associate Professor at Department of Electrical Engineering, Iqra National University, Peshawar. His research interests are Wireless Communications, Free Space Optics, MW Transmission Planning and designing, Signal and Information Processing, Micro-strip Antenna designing. He graduated in Computer Engineering from COMSATS Institute of Information Technology (CIIT), Islamabad in 2004. He received his master degree in Electrical Engineering from Blekinge Tekniska Högskola (BTH,) Karlskorna, Sweden in 2006 and got his Ph.D. degree in Electrical Engineering from Beijing University of Posts and Telecommunication, China in 2012. He is a reviewer of various scientific research journals and he has published over 29 research papers in scientific journals and in IEEE conferences related to Wireless Communications, Free Space Optics and Micro Strip Antenna designing, also he is the H.E.C Approved Supervisor.

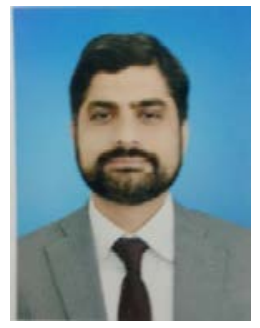

Mr. Mukhtar Ahmad received MSc degree in Electronics from Quaid-e-Azam University Islamabad, Pakistan in 2011. Then he received MS-CS Telecommunication and Networking from Gandhara University Peshawar in 2014. He is pursuing his $\mathrm{PhD}$ in Electrical Engineering from Capital University of Science and Technology (CUST) Islamabad Pakistan. Currently he is working as a Lecturer in Department of Electronics Islamia College Peshawar, Peshawar, Pakistan.

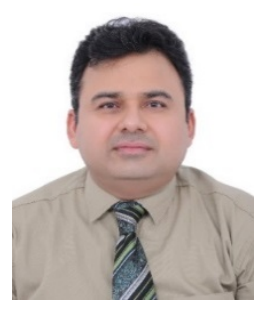

Dr. Muhammad Yousaf Ali Khan did his BSc Electrical Engineering from University of Engineering \&Technology, Peshawar, Pakistan in 2006. He did his MS and $\mathrm{PhD}$ in Electrical and Electronic System Engineering from Hanyang University, South Korea in 2010 and 2016 respectively. Currently, he has been working as Assistant Professor at the department of Electrical Engineering, Gomal University, D.I.Khan, Pakistan. He has vast experience of working in Academia, Industry and Research orgajzations. He has many publications in international and national journals. He remained session Chair for different IEEE Conferences and also working as a technical reviewer for different conferences and journals. 


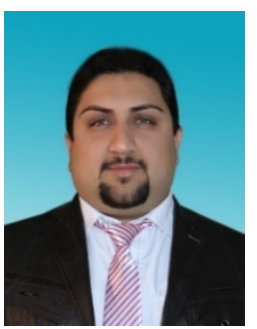

Dr. Asif Nawaz received his B.Sc in Electrical Engineering from University of Engineering and Technology Lahore in 1998, MBA-ITM from international Islamic University Islamabad in 2004, MS Computer Engineering from Lahore University of Management Sciences (LUMS) Lahore from 2006, PhD in Electromagnetic Field and Microwave Technology from Beijing University of Posts and Telecommunication (BUPT), Beijing, China in 2010, EMBA from Lahore University of Management Sciences (LUMS) in 2012. Presently he is working in HCT as Asst Professor of Electrical Engineering in Faculty of Engineering Technology and Sciences. His research interests are Machine Learning and Artificial Intelligence, IOT, ICT Transformation, Cloud Architecture, NFV/SDN, Next Generation Networks; Wireless Mesh Networks (WMNs); Satellite and Mobile Adhoc Networks (MANETs); Optical Wireless Hybrid Networks; Optical Networks (OBS, OPS); High Speed Transport Protocols; Mobile IP and IPV6 Deployment and Test beds, Network Management and Performance Evaluation and Telecom Project Management.

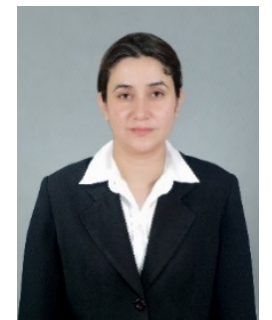

Rohi Tariq received the master's degree from the Department of Computer Science, Institute of Social policy and Research, Bacha Khan Univ. Pakistan, in 2019. She is currently a Ph. D joint scholar at School of Information and Technology, KMUTT, Bangkok and Faculty of Science, Technology and Medicine, University of Luxembourg, Luxembourg. Her research interests focus on Ad Hoc network, secure communications, and artificial intelligence. She also serving as IT professional, at department of Secondary and Elementary Education, KPK, Pakistan. 